\title{
Anisotropy of Thermal Fatigue Properties of Cold-Rolled TiNi Sheet
}

\author{
Ir. J. H. Mulder, ${ }^{\star}$ P. E. Thoma, ${ }^{\star}$ and J. Beyer* \\ *University of Twente, Faculty of Mechanical Engineering, Laboratory for Materials Science, \\ P.O. Box 217, 7500 AE Enschede, the Netherlands, and Johnson Controls, Inc., \\ 1701 West Civic Drive, A37, P.O. Box 591, Milwaukee, Wisconsin 53201-0591
}

The texture of cold-rolled and heat-treated TiNi sheet has been measured and designated as $\{110\}\langle 1 \overline{1} 0\rangle_{p}$. This material has been used in thermal fatigue tests during and after which the anisotropy and development of several thermomechanical properties, such as transformation temperatures and strains, have been measured. Furthermore, the resulting changes of texture after thermal fatigue are presented. The observed effects are explained on the basis of the parent texture and the specific martensite variants that are formed according to the lattice correspondence between austenite $(P)$ and martensite $(M)$.

\section{INTRODUCTION}

In the literature it has been shown that the thermomechanical properties of polycrystalline TiNi shape memory alloys (SMAs) can be readily influenced by creation of a certain texture [1-6]. Eucken and Hirsch [3,4] determined that the texture of hot-rolled TiNi sheet is near $\{110\}\langle 1 \overline{1} 0\rangle_{p}$. The same texture, although less profound, is also found in cold-rolled TiNi sheet, heat-treated below the recrystallization temperature [7]. It was shown that this texture leads theoretically to a maximum anisotropy of shape memory strains in the rolling plane [7]. This work will elucidate the influence of texture on thermomechanical behavior during and after temperature cycling under a constant tensile stress, hereafter referred to as thermal fatigue. It will be shown that, for the same material, a large variation of thermomechanical properties can be obtained depending on the orientation of the loading direction (LD) during service with respect to the original rolling direction (RD) of the sheet. The knowledge of these variations is useful for the selection of shape memory elements for specific applications.

\section{EXPERIMENTAL PROCEDURE}

The starting material used for cold rolling was a $1.3 \mathrm{~mm}$-thick TiNi plate supplied by Johnson Controls. The matrix composition of the as-received material was determined to be 50.8 at. \%Ti-49.2at. \%Ni with the use of microprobe analysis. The characteristic transformation temperatures of the as-received condition, recrystallized at $950^{\circ} \mathrm{C} / 1 \mathrm{~h}$, are $M_{s}=81^{\circ} \mathrm{C}, M_{f}=59^{\circ} \mathrm{C}, A_{s}=88^{\circ} \mathrm{C}$, and $A_{f}=110^{\circ} \mathrm{C}$, as determined by differential scanning calorimetry (DSC of PL Thermal Sciences) for the first cycle at $10^{\circ} \mathrm{C} / \mathrm{min}$. The cold rolling (10 steps) was concluded with a final $16 \%$ reduction and a $375^{\circ} \mathrm{C} / 1 \mathrm{~h}$ heat treatment (details in Mulder et al. [7]). After processing, the $\mathrm{R}$ phase transformation $\mathrm{P} \rightarrow \mathrm{R}$ became distinct on cooling. The transformation temperatures, as determined by calorimetry, are $R_{s}=62^{\circ} \mathrm{C}, R_{p}=56^{\circ} \mathrm{C}, R_{f}=$ $48^{\circ} \mathrm{C}, M_{s}=28^{\circ} \mathrm{C}, M_{p}=7^{\circ} \mathrm{C}, M_{f}=-16^{\circ} \mathrm{C}$, 
$A_{s}=51^{\circ} \mathrm{C}, A_{p}=64^{\circ} \mathrm{C}$, and $A_{f}=77^{\circ} \mathrm{C}$ [see Fig. 7(a)]. The $p$ subscript refers to the location of the peak on the DSC curve.

Tensile specimens (effective size $0.36^{*} 3.5^{\star}$ $50 \mathrm{~mm}^{3}$ ) were spark cut in directions $\alpha=0$, $35,50,70$, and $90^{\circ}$ to RD, to be used as LD during the thermal fatigue tests. The oxide layer was removed from the specimens by electropolishing in a Struers A8 at 70V.

The thermal fatigue tests were carried out on a Zwick tensile machine at a controlled stress level of $150 \mathrm{MPa}$. After fixed numbers of cycles at $150 \mathrm{MPa}$, a thermal cycle at $15 \mathrm{MPa}$ was recorded, hereafter referred to as the "two-way"-memory cycle. After cycle number 1700,10 more cycles were run additionally at $150 \mathrm{MPa}$, and then the test was stopped. Loading and unloading of the specimens was always done in the martensitic condition at $225 \mathrm{~N} / \mathrm{min}$. Direct resistance heating with currents ranging from 12 to $15 \mathrm{~A}$ was used to heat the specimen up to $150^{\circ} \mathrm{C}$ in $10 \mathrm{~s}$. The cooling was enhanced by an air fan, and a temperature of about $30^{\circ} \mathrm{C}$ was achieved in $30 \mathrm{~s}$. The strain was measured with a strain gauge (Materials Test Systems) with a measurement length of $25 \mathrm{~mm}$. The temperature of the specimens was recorded with a chromel-alumel thermocouple, spotwelded on the specimen. Because the heating current influenced the temperature signal, a correction was made on the temperature data on heating. In spite of this correction, the represented temperatures during heating are only accurate within $\pm 5^{\circ} \mathrm{C}$.

After the thermal fatigue tests, two specimens of about $10 \mathrm{mg}$ each were cut from the central section of each tensile specimen with a low-speed boron nitride saw. These specimens were used to determine the transformation behavior after thermal fatigue by calorimetry.

Textures were measured with a Philips $X$-ray texture goniometer with $\mathrm{Co}-\mathrm{K}_{\alpha}$ radiation. Pole figures of $\{110\}_{P},(020)_{M},(11 \overline{1})_{M}$, and $(111)_{M}$ were recorded up to $\phi=80^{\circ}$ with a pitch of $5^{\circ}$. The martensite textures after thermal fatigue were measured from the back side of the specimens, and, therefore, the specimen direction is referred to as $-\alpha$ in the figures related to these martensite textures.

\section{RESULTS}

A strain-temperature graph resulting from the thermal fatigue test at cycle 25 for $\alpha=$ $0^{\circ}$ is shown in Fig. 1. The definitions of $\varepsilon_{M}$ (strain at minimum temperature), $\varepsilon_{\mathrm{P}}$ (strain at $120^{\circ} \mathrm{C}$ during cooling), $M_{m}$ (temperature at $1 / 2\left(\varepsilon_{M}-\varepsilon_{P}\right)$ during cooling), and $A_{m}$ (temperature at $1 / 2\left(\varepsilon_{M}-\varepsilon_{P}\right)$ during heating) are elucidated on the fatigue cycle (150MPa, curve 1). These definitions also apply to the "one-way" half cycle (curve 2, $15 \mathrm{MPa}, M_{m}$ does not apply) and the "two-way" cycle (curve 3, 15MPa). The transformation temperatures are taken as temperatures at half of the transformation strain, because in this way unique and easy-to-determine values are obtained.

During thermal fatigue, the stress-strain curves of the loading of the martensite show a diminishing plateau stress as well as a diminishing plateau strain, with increasing number of cycles, as shown in Fig. 2 for $\alpha=0^{\circ}$. This is accompanied by the development of a "two-way" memory effect $\left(\varepsilon_{M}-\varepsilon_{P}\right)_{15 \mathrm{MPa}}$ during the thermal fatigue, as can be derived from Fig. 3. This figure shows the development of $\varepsilon_{M}$ and $\varepsilon_{P}$ for both the fatigue and "two-way" memory, and the development of the stress-induced strain during loading with increasing number of cycles. The stress-induced strain is

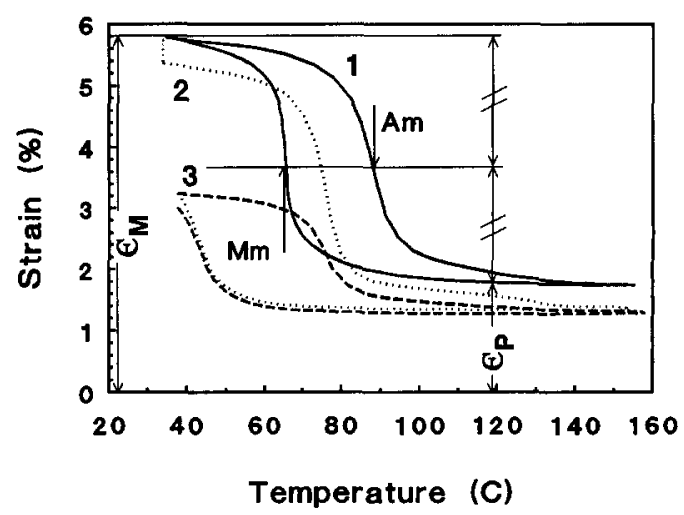

Fig. 1. Strain-temperature curves from the thermal fatigue tests for $\alpha=0^{\circ}$ at cycle number 25, with: curve 1: fatigue cycle at $150 \mathrm{MPa}$, curve 2 : "one-way" cycle at $15 \mathrm{MPa}$, and curve 3: "two-way" cycle at $15 \mathrm{MPa}$. 


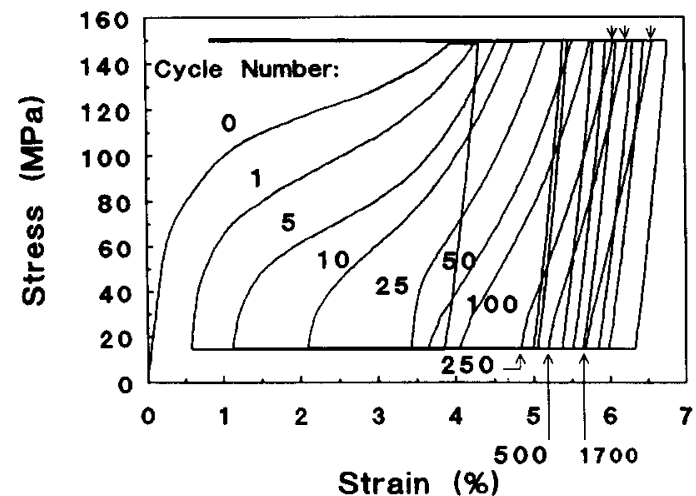

FIG. 2. Stress strain graph of all loadings and unloadings during the thermal fatigue test for $\alpha=0^{\circ}$.

defined as $\left(\varepsilon_{M, 150 \mathrm{MPa}}-\varepsilon_{M, 15 \mathrm{MPa}}\right)$, where $\varepsilon_{M, 15 \mathrm{MPa}}$ and $\varepsilon_{M, 150 \mathrm{MPa}}$ are the values of the strain at $15 \mathrm{MPa}$ and $150 \mathrm{MPa}$ at low temperature just before and after the specimen is loaded. After an initial increase (not presented) of the fatigue transformation strain $\left(\varepsilon_{M}-\varepsilon_{p}\right)_{150 \mathrm{MPa}}$ to a maximum in the first three or four cycles, it starts to decrease with increasing number of cycles as a consequence of the thermal fatigue. The "twoway" memory $\left(\varepsilon_{M}-\varepsilon_{P}\right)_{15} \mathrm{MPa}$ increases steadily, while the induced strain decreases steadily during the test.

Figure $4(a-c)$ shows the resulting anisotropy of $\left(\varepsilon_{M}-\varepsilon_{P}\right)_{150 \mathrm{MPa}}\left(\varepsilon_{M}-\varepsilon_{P}\right)_{15 \mathrm{MPa}}$ and $\varepsilon_{P, 15 \mathrm{MPa}}$ all taken relative to the fatigue transformation strain in cycle 10 of the respective direction $\alpha$. This results in compa-

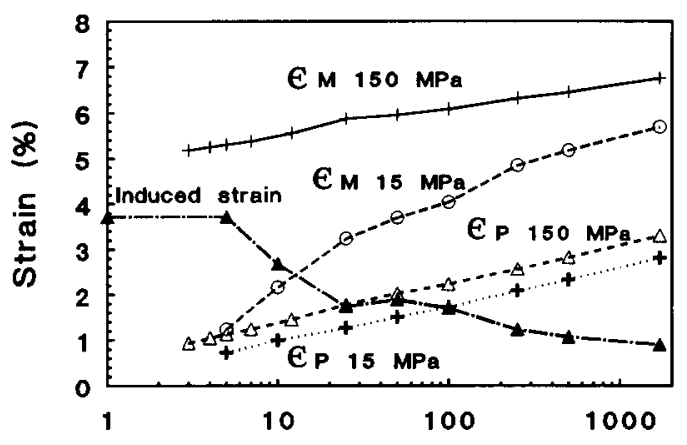

\section{Number of cycles}

FIG. 3. Development of the induced strain and the austenite and martensite strains during thermal fatigue for $\alpha=0^{\circ}$.

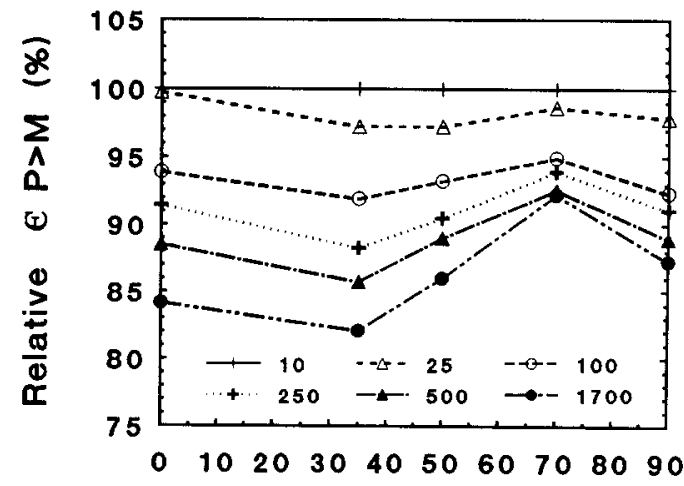

Angle to RD (deg)

(a)

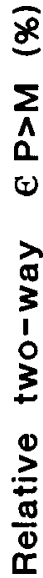

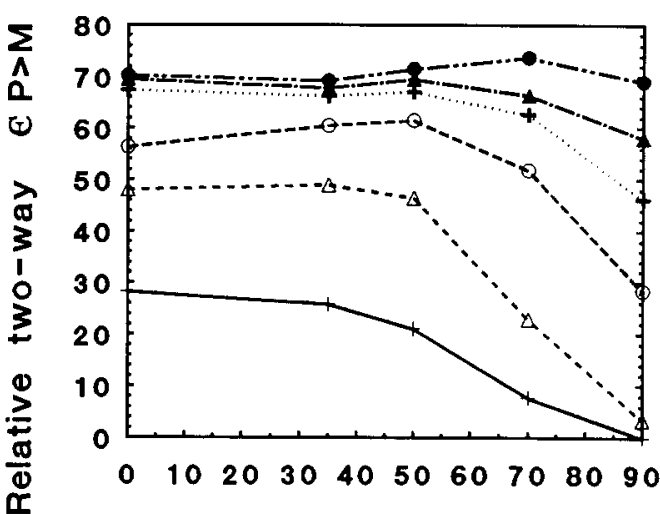

Angle to RD (deg)

(b)

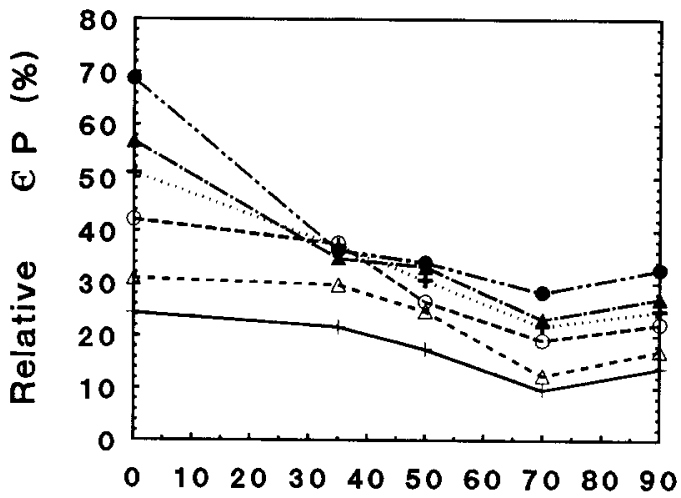

\section{Angle to RD (deg)}

(c)

F1G. 4. Anisotropy of the development of: (a) the relative fatigue transformation strain $100 \%\left(\varepsilon_{M}-\varepsilon_{\mathrm{P}}\right)_{150 \mathrm{MPa}}$

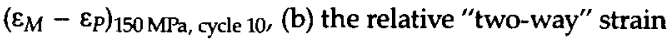
$100 \%\left(\varepsilon_{M}-\varepsilon_{P}\right)_{15} \mathrm{MPa} /\left(\varepsilon_{M}-\varepsilon_{P}\right)_{150} \mathrm{MPa}$, cycle 10 , and (c) the relative parent strain $100 \%\left(\varepsilon_{P, 15} \mathrm{MPa}\right) /\left(\varepsilon_{M}-\right.$

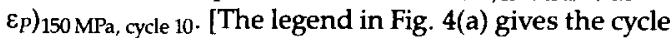
numbers.] 
rable measures for fatigue memory development ( $100 \%$ minus memory loss), two-way memory development, and creep, respectively. The reference transformation strain values $\left(\varepsilon_{M}-\varepsilon_{P}\right)_{150} \mathrm{MPa}$, cycle 10 are $4.10,4.35$, $4.00,2.97$, and $2.36 \%$, respectively, for the directions $\alpha=0,35,50,70$, and $90^{\circ}$. The memory loss [Fig. 4(a)] of the directions around the transverse direction (TD) is smaller compared with the RD; especially $\alpha=70^{\circ}$ is favorable. The "two-way" memory effect [Fig. 4(b)] is seen to develop much slower in directions near the TD as compared with the RD, but it reaches the same final value as the RD. The creep [Fig. 4(c)] is shown to be also much smaller for directions near the TD. The negative creep in direction $\alpha=35^{\circ}$ after cycle 100 is attributed to a sudden slip of the strain gauge.

Figure 5 shows the development of the $A_{m}$ and $M_{m}$ temperatures for the fatigue, "twoway," and "one-way" ( $A_{m}$ only) cycles with increasing cycle number, for $\alpha=0^{\circ}$. Figure $6(a, b)$ shows the anisotropy of the development of the $M_{m}$ temperatures during thermal fatigue cycles and during "two-way" memory cycles. The initial fatigue $M_{m}$ temperatures are about $20^{\circ} \mathrm{C}$ higher than the initial "two-way" $M_{m}$ temperatures, showing the same anisotropy: The $M_{m}$ temperatures are relatively low for directions near TD as compared with RD. The fatigue $M_{m}$ temperatures increase steadily with increas-

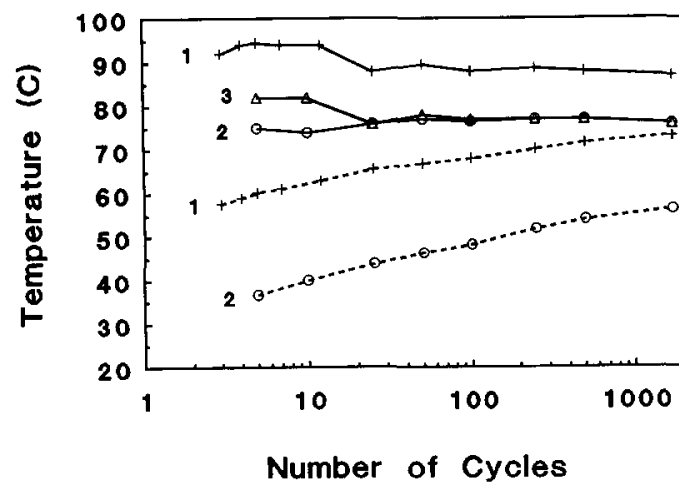

FIG. 5. Development of transformation temperatures during the thermal fatigue test, with: curves 1 : fatigue cycle (150MPa), $A_{m}$ solid, $M_{m}$ dashed; curves 2: "twoway" cycle (15MPa), $A_{m}$ solid, $M_{m}$ dashed; and curve 3: "one-way" cycle (15MPa), $A_{m}$ solid.

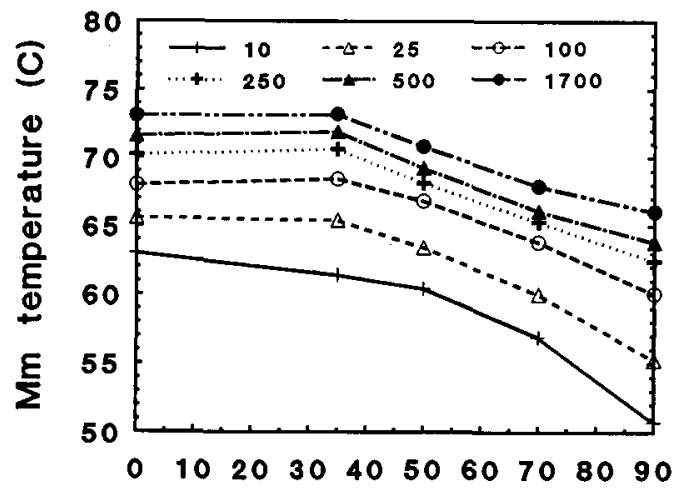

Angle to RD (deg)

(a)

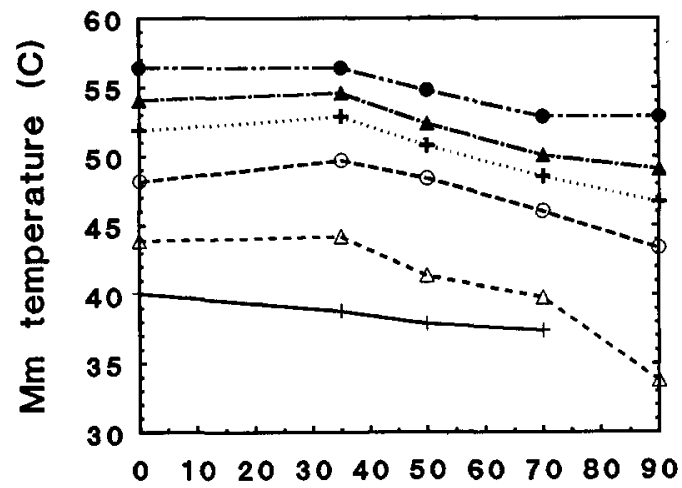

Angle to RD (deg)

(b)

Fig. 6. Anisotropy of the development of $M_{m}$ temperatures, for: (a) the fatigue cycle (150MPa), and (b) the "two-way" cycle (15MPa). [The legend in Fig. 6(a) gives the cycle numbers.]

ing number of cycles, the anisotropy being preserved. The "two-way" $M_{m}$ temperatures also increase with increasing cycle number, but here the $M_{m}$ temperatures of directions near TD catch up with those of RD. Although the $A_{m}$ temperatures were determined with limited accuracy, it can be stated that for all $\alpha$, they show a much smaller dependence on number of cycles. Therefore, the hysteresis $A_{m}-M_{m}$ is effectively decreasing with increasing number of cycles.

The thermal transformation behavior of the fatigued material as determined on a DSC [Fig. 7(b), $\left.\alpha=0^{\circ}\right]$ is connected with 


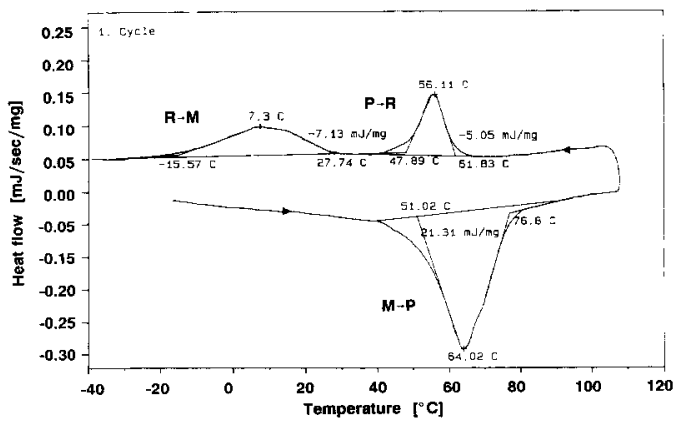

(a)

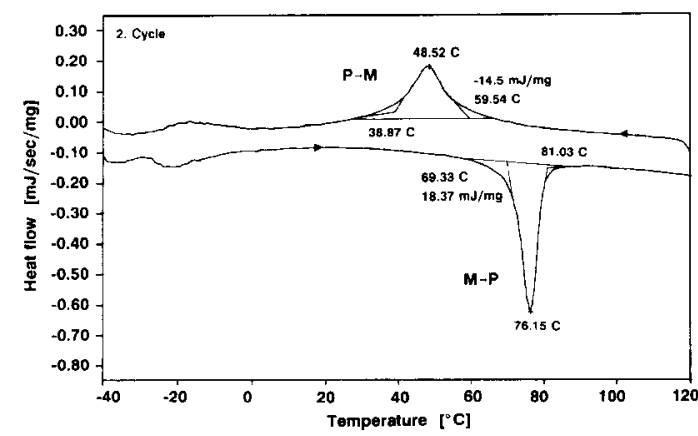

(b)

FIG. 7. DSC curves taken at $10^{\circ} \mathrm{C} / \mathrm{min}$ of (a) the as-rolled and heat-treated material $\left(16 \%+375^{\circ} \mathrm{C} / 1 \mathrm{~h}\right)$ and of (b) the fatigued material with $\alpha=0^{\circ}$.

a real (0MPa) two-way memory effect. Comparing this with the behavior of the as-heattreated condition (Fig. 7a), it appears that the transformation temperatures have indeed increased during thermal fatigue, $M_{P}$ about $35^{\circ} \mathrm{C}$ and $A_{P}$ about $10^{\circ} \mathrm{C}$. The transformation on cooling has changed from twostage to predominant single stage, because the $R \rightarrow M$ peak has merged into the $P \rightarrow R$ peak.

The transformation temperatures after thermal fatigue as measured by calorimetry also show limited anisotropy, as shown in Fig. 8. The $M_{P}$ temperature shows an angular dependence similar to both the $M_{m}$ temperature of the fatigue cycle and the $M_{m}$ temperature of the "two-way" cycle, and thus is lower for directions $\alpha>35^{\circ}$. Strikingly, however, the $A_{P}$ temperature is maximum between $\alpha=35^{\circ}$ and $\alpha=90^{\circ}$, and the thermal hysteresis $A_{P}-M_{P}$ is smallest for $\alpha=35^{\circ}$.

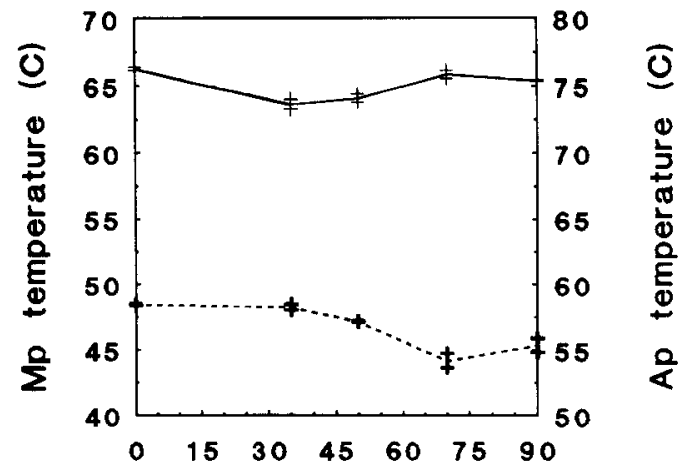

Angle to RD (deg)

FIG. 8. Anisotropy of DSC transformation temperatures $A_{p}$ (solid) and $M_{p}$ (dashed) after thermal fatigue (second cycle values of two specimens, line through means).

Because of the presence of the $R$ phase at room temperature in the processed material, $\{110\}_{P / R}$ has been used to determine the austenite texture. The texture was designated as $\{110\}\langle 1 \overline{1} 0\rangle_{P}[7]$, with a spread of the central $\{110\}_{P / R}$ intensity in the TD. This material was shown [7] to contain four different martensite textures A-D after cooling to $-25^{\circ} \mathrm{C}$. These textures consist of the following martensite correspondence variants (variant notation according to Miyazaki et al. [8], with (110)[110]p as the parent texture):
A: $(111)[(1 \overline{1} \overline{1})]_{M}: 1^{\prime}, 2^{\prime}, 3,4^{\prime}$,
B: $(11 \overline{1})[(1 \overline{1} 1)]_{M}: 1,2,3^{\prime}, 4$,
C: $(010)[(001)]_{M}: 5,5^{\prime}$,
D: $(001)[(010)]_{M}: 6,6^{\prime}$.

In Mulder et al. [6], the as-measured $(020)_{M}$ pole figures after thermal fatigue for $\alpha=0^{\circ}$ and $35^{\circ}$ were presented. Figure $9(a, b)$ shows the as-measured $(111)_{M}$ pole figure for $\alpha=$ $35^{\circ}$ and the $(11 \overline{1})_{M}$ pole figure for $\alpha=90^{\circ}$. As pointed out in Mulder et al. [6], the specimen with $\alpha=0^{\circ}$ shows a preferred martensitic texture of type $C$, while for $\alpha=90^{\circ}$ both type $A$ and type $B$ are present. The directions in-between show textures that are asymmetric with respect to planes normal to the TD and $R D$, due to preferred variant selection. Table 1 summarizes the correspondence variants present in the different directions $\alpha$, as derived from the texture measurements. 


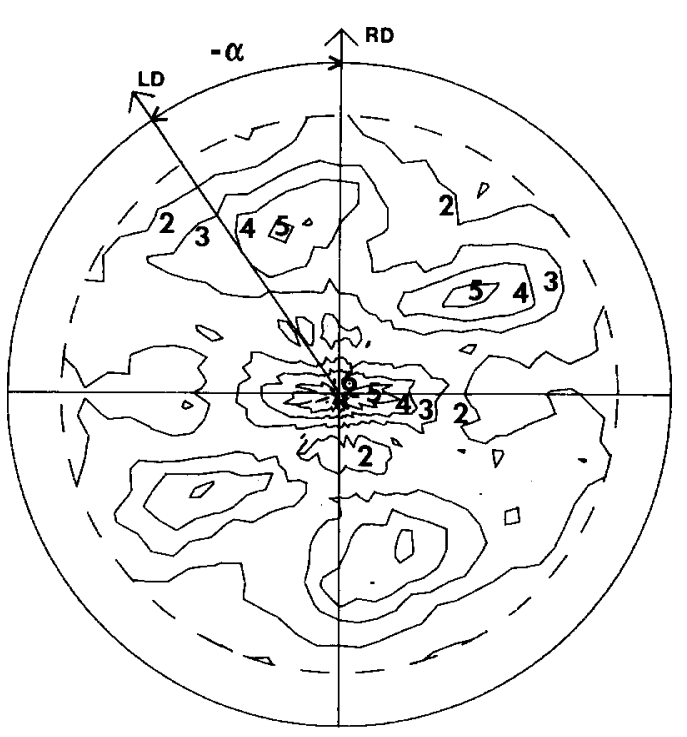

(a)

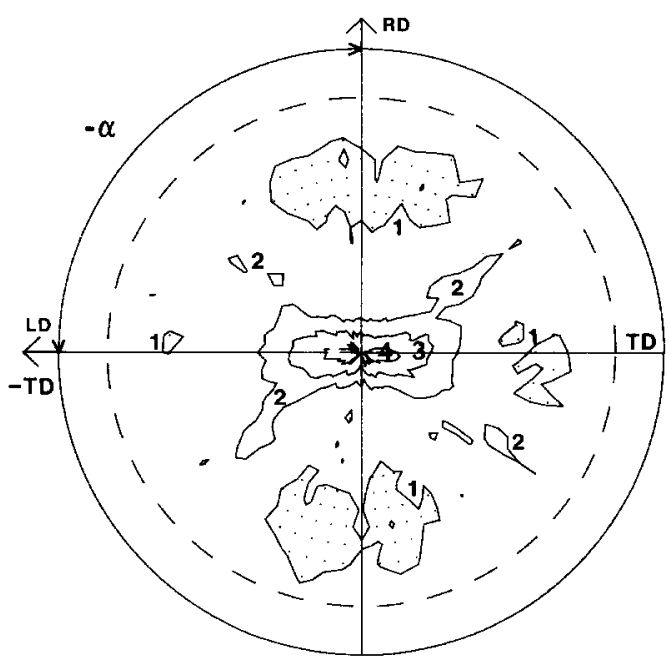

(b)

Fig. 9. Pole figures of fatigued specimens, (a) (111) $)_{M}$ for $\alpha=35^{\circ}$, and (b) (111) $)_{M}$ for $\alpha=90^{\circ}$; LD is the loading direction.

The amount of variants 5 and $5^{\prime}$ is maximum for $\alpha=0^{\circ}$ and decreases with increasing angle to $R D$. The amount of variants 3 and $2^{\prime}$ increases from $\alpha=0^{\circ}$ to a maximum at $\alpha=50^{\circ}$ and then decreases to $\alpha=90^{\circ}$. The central intensity in the $(111)_{M}$ pole figure of $\alpha=35^{\circ}$ [Fig. 9(a)] proves the presence of texture $A$. The asymmetry of the offcentral $(020)_{M}$ intensities for $\alpha=35^{\circ}$ (see Mulder et al. [6]), lying in directions approx-
Table 1 Measured Variants in Fatigued Specimens, Indexed on (110) $[1 \overline{1} 0]_{p}$

\begin{tabular}{rll}
\hline$-\alpha\left({ }^{\circ}\right)$ & Variants & $\begin{array}{c}\text { Part of } \\
\text { Texture }\end{array}$ \\
\hline 0 & $5,5^{\prime}$ & $\mathrm{C}$ \\
-20 & $3,2^{\prime} / 5^{\prime}$ & $\mathrm{A} / \mathrm{C}$ \\
-35 & $3,2^{\prime} / 5^{\prime}$ & $\mathrm{A} / \mathrm{C}$ \\
-50 & $3,2^{\prime} / 2,3^{\prime}$ & $\mathrm{A} / \mathrm{B}$ \\
-70 & $3,2^{\prime} / 2,3^{\prime}$ & $\mathrm{A} / \mathrm{B}$ \\
-90 & $2,3^{\prime} / 3,2^{\prime}$ & $\mathrm{B} / \mathrm{A}$ \\
\hline
\end{tabular}

Variant notation according to Miyazaki et al. [8]; variants after the / (virgule) are present to a lesser extent.

imately normal to $\mathrm{LD}$, proves that variants 3 and $2^{\prime}$ are present and not $1^{\prime}$ and $4^{\prime}$, while the central $(020)_{M}$ intensity proves the presence of variant $5^{\prime}$. The amount of variants 2 and $3^{\prime}$ is increasing from $\alpha=50^{\circ}$ to $\alpha=$ $90^{\circ}$. The central (111) $)_{M}$ intensity [Fig. 9(b)] for $\alpha=90^{\circ}$ proves the presence of variants 2 and $3^{\prime}$ for this direction.

\section{DISCUSSION}

The martensite variant selection of the fatigued specimens is expected to be governed by a criterion of maximum transformation strain. Figure 10 shows the theoretical anisotropy of transformation strains of three correspondence variants with maximum transformation strain originating from textures $(110)[1 \overline{1} 0]_{P}$ and $(22 \overline{1})[1 \overline{1} 0]_{P}$. The texture $(22 \overline{1})[1 \overline{1} 0]_{P}$ can be obtained from $(110)[1 \overline{1} 0]_{P}$ by a rotation of about $19.5^{\circ}$ around RD and is included to illustrate the influence of the spread of the central $\{110\}_{P}$ in the TD. For (110) $[110]_{P}$, variant $5^{\prime}$ is favorable for angles 0 to $-35^{\circ}$ to $\mathrm{RD}$, and variants 3 and $2^{\prime}$ are favorable from -35 to $-90^{\circ}$ to RD. For the TD of $(22 \overline{1})[1 \overline{1} 0]_{P}$, the variants 2 and $3^{\prime}$ are more favorable than variants 3 and $2^{\prime}$. Thus, the measured sequence of major variants of $5^{\prime}-\left(2^{\prime}, 3\right)-\left(2,3^{\prime}\right)$ from RD to - TD corresponds with a sequence of theoretically favorable variants with respect to maximum transformation strain.

The creep occurring during thermal fatigue 


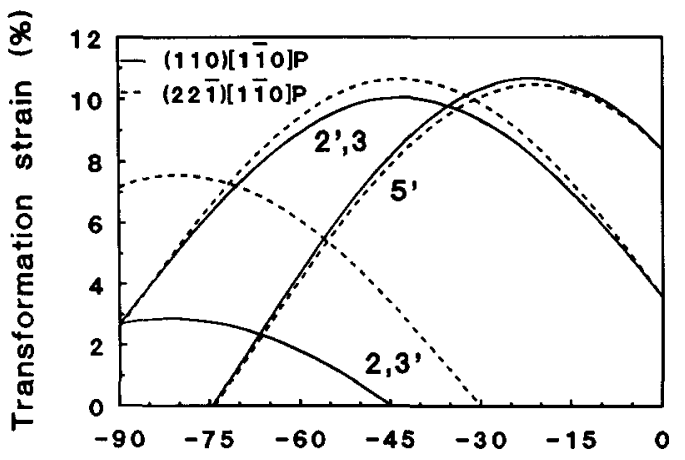

Angle to RD (deg)

FIG. 10. Theoretical anisotropy $\left(-\alpha\right.$ from $-90^{\circ}$ to $\left.0^{\circ}\right)$ of maximum transformation strains for $(110)[1 \overline{1} 0]_{P}$ and $(22 \overline{1})[1 \overline{1} 0]_{p}$; the formed correspondence variants are indicated.

is caused by dislocation generation and slip, leading to a certain dislocation rearrangement. The creep is proven to be connected with both the development of "two-way" memory and with memory loss. Directions near the TD, which show limited creep, also show a slow initial "two-way" memory increase, and a limited memory loss, as compared with other directions. The dislocation rearrangements are, therefore, held responsible for the "two-way" memory, inducing particular martensite variants on cooling. The increasing dislocation density is held responsible for the fatigue memory loss.

The increase of transformation temperatures during thermal fatigue, especially the $M_{s}, M_{m}, M_{p}$, and $M_{f}$ temperatures, can be regarded as stabilization of the martensite phase. This stabilization itself is both reflected at $150 \mathrm{MPa}$ and $15 \mathrm{MPa}$. However, the anisotropy of the stability of the martensite remains at $150 \mathrm{MPa}$, while it decreases at $15 \mathrm{MPa}$. The increase of the martensite transformation temperatures causes the $\mathrm{R}$ phase formation to be unresolved by calorimetry after the thermal fatigue test.

The anisotropy of transformation temperatures $\left(M_{m}\right)$ at $150 \mathrm{MPa}$ during thermal fatigue is caused by differences in the effectiveness of the applied load for martensite induction and stabilization, as pointed out in Mulder et al. [6]. The Schmid factor $\gamma$ for induction of a martensite habit plane vari-

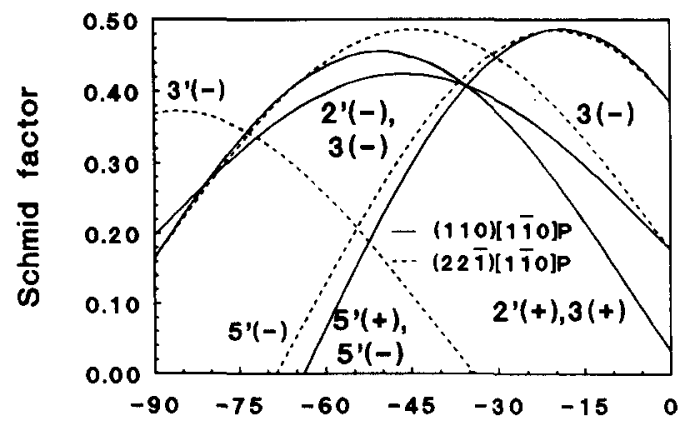

Angle to RD (deg)

Fig. 11. Theoretical anisotropy $\left(-\alpha\right.$ from $-90^{\circ}$ to $\left.0^{\circ}\right)$ of the Schmid factor $\gamma$ for induction of the most favorable habit plane variants for $(110)[1 \overline{1} 0]_{P}$ and $(22 \overline{1})[1 \overline{1} 0]_{P}$; $\gamma=\tau_{\text {habit plane }} / \sigma_{L D}=\cos (L D, \mathbf{n}) \times \cos (L D, d)$, where $\sigma_{L D}$ is the applied tensile stress, $\tau_{\text {habit plane }}$ is the effective shear stress on the habit plane, $\mathbf{n}$ is the habit plane normal, and $\mathbf{d}$ is the deformation direction (habit plane variant formation according to [011]/[011] type II twinning; see Miyazaki et al. [8]).

ant relates the applied tensile stress to the resolved shear stress on the habit plane in the deformation direction. As shown in Fig. 11 for the parent texture $(110)[1 \overline{1} 0]_{P}$, the maximum $\gamma$ varies between 0.38 and 0.48 near RD for variants $5^{\prime}(-)$ and $5^{\prime}(+)$ but decreases, via variants $2^{\prime}(+)$ and $3(+)$, down to 0.2 in TD for variants $2^{\prime}(-)$ and $3(-)$. (Detwinning would result in an ideal sequence of correspondence variants as presented in Fig. 10.) Therefore, directions near RD form a relatively stable martensite under a tensile stress as compared with directions near TD.

The angular dependence of $M_{m}$ during thermal fatigue remains relatively constant, irrespective of the number of cycles. This means that the development of the "twoway" memory during the thermal fatigue test hardly influences the relative stabilities of the martensites of the different directions $\alpha$ at $150 \mathrm{MPa}$.

The anisotropy of the increase of the "twoway" memory effect is directly related to the anisotropy of the increase of the "two-way" $M_{m}$ temperatures. Directions near TD start with a small initial "two-way" effect and with low initial "two-way" $M_{m}$ temperatures, but both properties are increasing up to the values of $R D$. 
The anisotropy of the "real" two-way memory transformation temperatures (DSC, $0 \mathrm{MPa}$ ) could possibly be annihilated by even longer training. The fact that the hysteresis $A_{p}-M_{p}$ of the trained material is lowest for $\alpha=35^{\circ}$ might be related to the fact that for this direction, two groups of martensite correspondence variants are favorably formed. As pointed out in Fig. 10, both sets variants $\left(2^{\prime}, 3\right)$ and $\left(5^{\prime}\right)$ are equally favored for $\alpha=35^{\circ}$. Apart from providing the maximum trained shape strain in the loading direction, the two sets of variants forming in this direction would be able to provide better self-accommodation with respect to the directions normal to LD. This might be the cause of the two-way effect being more thermoelastic for $\alpha=35^{\circ}$ as compared with other directions.

It has been shown that the presence of an austenite texture in TiNi sheet material can result in formation of different martensite textures and in a related and appreciable variation of thermomechanical properties if different directions within the rolling plane are subjected to thermal fatigue testing. These differences have important technological implications for training procedures and, for example, for actuator applications. Therefore, the formation of texture during processing and the relation between texture, martensite variant selection, and thermoelastic properties of TiNi-based SMAs will be the subject of further and more extensive investigations.

\section{CONCLUSIONS}

The texture of cold-rolled and heat-treated TiNi sheet is shown to have an influence on thermal fatigue properties. The directions near the TD show a favorable thermal fatigue behavior, with relatively low creep and small memory loss. However, the development of "two-way" memory is also slow. The transformation temperatures are shown to increase during thermal fatigue due to stabilization of specific martensite variants. The martensite variant selection during thermal fatigue is shown to be governed by maximization of the transformation strain.

The authors express their gratitude to Johnson Controls, Inc. for financial support and for supplying the material.

\section{References}

1. R. G. De Lange and J. A. Zijderveld, Shapememory effect and the martensitic transformation of TiNi, J. Appl. Phys. 39:2195-2200 (1968).

2. L. A. Monasevich, Yu I. Paskal, V. E. Prib, G. D. Timonin, and D. B. Chernov, Effect of texture on the shape memory effect in titanium nickelide, Metalloved. Term. Obrab. Met. 9:62-63 (1979).

3. S. Eucken and J. Hirsch, Austenite textures in Ni-Ti and Cu-based shape memory alloys, in The Martensitic Transformation in Science and Technology, E. Hornbogen and N. Jost, eds., DGM-Verlag, Oberursel, Germany, pp. 333-340 (1989).

4. S. Eucken and J. Hirsch, The effect of textures on shape memory behaviour, Mat. Sci. Forum 56-58: 487-492 (1990).

5. D. Y. $\mathrm{Li}, \mathrm{X} . \mathrm{F} . \mathrm{Wu}$, and T. Ko, The texture of Ti$51.5 \mathrm{at} \% \mathrm{Ni}$ rolling plate and its effect on the allround shape memory effect, Acta Metall. 38:19-24 (1990).

6. J. H. Mulder, P. E. Thoma, and J. Beyer, Anistropy of tensile recovery stress and two way memory effect of cold rolled TiNi sheet, in Mat. Res. Soc. Symp. Proc., Boston, MA, (December 2-6, 1991), pp. 195-200.

7. J. H. Mulder, P. E. Thoma, and J. Beyer, Anisotropy of the shape memory effect in tension of cold-rolled $50.8 \mathrm{Ti} 49.2 \mathrm{Ni}$ (at.\%) sheet, Z. Metallkunde 84: 501-508 (1993).

8. S. Miyazaki, K. Otsuka, and C. M. Wayman, The shape memory mechanism associated with the martensitic transformation in TiNi alloys-1. selfaccommodation, Acta Metall. 37:1873-1884 (1989).

Received June 1993; accepted December 1993. 